Systematic Review

Revisão Sistemática

Ana Luiza Gomes Pinto Navas ${ }^{1}$

Érica de Cássia Ferraz ${ }^{2}$

Juliana Postigo Amorina Borges²

\section{Phonological processing deficits as a universal model for dyslexia: evidence from different orthographies}

\author{
Déficit em processamento fonológico como um modelo universal \\ para a dislexia: evidência a partir de diferentes ortografias
}

Keywords

Dyslexia

Education

Language

Reading

Review

Descritores

Dislexia

Educação

Linguagem

Leitura

Revisão
Correspondence address:

Ana Luiza Gomes Pinto Navas

Faculdade de Ciências Médicas da Santa Casa de São Paulo

Rua Doutor Cesário Motta Júnior, 61, $8^{\circ}$ andar, Vila Buarque, São Paulo (SP), Brazil, CEP: 01221-020.

E-mail:ana.navas@fcmsantacasasp.edu.br

Received: 08/14/2014

Accepted: 10/13/2014

\begin{abstract}
Purpose: To verify the universal nature of the phonological processing deficit hypothesis for dyslexia, since the most influential studies on the topic were conducted in children or adults speakers of English. Research strategy: A systematic review was designed, conducted and analyzed using PubMed, Science Direct, and SciELO databases. Selection criteria: The literature search was conducted using the terms "phonological processing" AND "dyslexia" in publications of the last ten years (2004-2014). Data analysis: Following screening of (a) titles and abstracts and (b) full papers, 187 articles were identified as meeting the preestablished inclusion criteria. Results: The phonological processing deficit hypothesis was explored in studies involving several languages. More importantly, we identify studies in all types of writing systems such as ideographic, syllabic and logographic, as well as alphabetic orthography, with different levels of orthographyphonology consistency. Conclusion: The phonological processing hypothesis was considered as a valid explanation to dyslexia, in a wide variety of spoken languages and writing systems.
\end{abstract}

\section{RESUMO}

Objetivo: Verificar a natureza universal da hipótese do déficit de processamento fonológico para a dislexia, uma vez que os estudos mais influentes sobre o tema foram conduzidos com crianças ou adultos falantes do Inglês. Estratégia de pesquisa: Uma revisão sistemática foi planejada, conduzida e analisada utilizando as bases de dados PubMed, Science Direct e SciELO. Critérios de seleção: A busca da literatura foi conduzida utilizando os termos "phonological processing" e "dyslexia", nas publicações dos últimos dez anos (2004-2014). Análise dos dados: Após a triagem inicial (a) dos títulos e resumos e (b) do texto completo, identificamos 187 artigos que atenderam os critérios de inclusão. Resultados: A hipótese do déficit de processamento fonológico foi explorada em estudos envolvendo vários idiomas e, mais importante, em representantes de todos os tipos de sistemas de escrita como o ideográfico, silábico e logográfico, bem como ortografias alfabéticas, com variados níveis de consistência ortográfico-fonológica. Conclusão: A hipótese do processamento fonológico foi considerada como explicação válida para a dislexia em uma grande variedade de idiomas e sistemas de escrita.

Study carried out at the School of Speech-Language Pathology and Audiology, School of Medical Sciences, Santa Casa de São Paulo - FCMSCSP - São Paulo (SP), Brazil.

(1) School of Speech-Language Pathology and Audiology, School of Medical Sciences, Santa Casa de São Paulo FCMSCSP - São Paulo (SP), Brazil.

(2) Graduate program in Human Communication's Health, School of Medical Sciences, Santa Casa de São Paulo - FCMSCSP - São Paulo (SP), Brazil.

Conflict of interests: nothing to declare. 


\section{INTRODUCTION}

Dyslexia is a neurodevelopmental disorder with a strong genetic predisposition, characterized by specific difficulties in reading and spelling that could not be attributable to cognitive disabilities, lack of educational opportunities, socio-cultural environment, or obvious neurological deficits.

Within the past decades, several theories have been proposed in order to explain the diversity of linguistic and cognitive symptoms observed in developmental dyslexia. These theories conceptualize dyslexia as related to deficits that are either phonological, attentional, visual-magnocellular, auditory, or related to automatic learning ${ }^{(1)}$.

Even though there is a variety of approaches for explaining dyslexia symptoms, phonological processing difficulty has been the major theory explaining such cognitive deficits in dyslexia ${ }^{(2)}$. The phonological deficit hypothesis suggests that reading deficits can be attributed to a core deficit in manipulating linguistic information, at the phonological level, such as phonological awareness, or the ability to determine the constituent sounds which comprise spoken words. This deficit in phonological awareness leads to difficulty in learning grapheme-phoneme correspondences early on and to later difficulty in learning, decoding skills and spelling ${ }^{(3)}$. This evidence has largely come from children with difficulties in learning to read in English, a process that has similarities and differences with other languages ${ }^{(4)}$.

Whether this is a universal model to explain different manifestations, in all ages, spoken or written language contexts remain to be investigated. There have been several different accounts either contradictory or complementary to the phonological processing deficit hypothesis. The majority of studies examining the effects of auditory and visual processing deficits in dyslexia have been conducted in English, an opaque orthography. Therefore, it is essential to determine whether cognitive characteristics, such as the phonological deficits in dyslexia, may differ across languages varying in orthographic consistency.

\section{PURPOSE}

The purpose of the study was to determine whether there is enough evidence in the literature for a phonological processing deficit model for explaining dyslexia, in a wide range of writing systems and orthographies. The approach adopted was a systematic review of studies that relate phonological processing and dyslexia.

\section{RESEARCH STRATEGY}

The central question was to analyse the universal validity of the phonological processing deficit hypothesis for explaining dyslexia, regardless of the spoken language, writing system or age of population. Furthermore, the review describes whether the evidence for phonological processing difficulties comes from experimental, theoretical or intervention studies.
We conducted a search for articles in PubMed, Science Direct and SciELO, published over the past ten years, in Portuguese or English, with the combination of the terms "phonological processing" AND "dyslexia" and their equivalents in Portuguese ("processamento fonológico" AND “dislexia"). The search was performed using the advanced form, in all indices, with items sorted by relevance. On PubMed and Science Direct, two separate searches were conducted: one considering only the articles with open access and also considering other items with restricted access. For PubMed and Science Direct with restricted access, we selected only the 100 most relevant articles of each database. Duplicated articles were excluded from the final sample.

\section{SELECTION CRITERIA}

We adopted as selection criteria for the analysis the inclusion of complete original articles and review articles, published in the last ten years (from January 2004 to April 2014), in Portuguese or English. The following combination of terms was used for the search: "phonological processing" AND "dyslexia" and their corresponding terms in Portuguese "processamento fonológico" AND "dislexia". We included general studies on dyslexia and other known comorbidities, such as attention deficit hyperactive disorder (ADHD), specific language impairment (SLI), dyscalculia and dysgraphia. We excluded repeated articles, articles that were not related to the topic, publications on acquired dyslexia, aphasia, psychiatric or neurological diseases, as well as other irrelevant topics for the current discussion (reading difficulties in Down syndrome, Williams syndrome etc.).

\section{DATA ANALYSIS}

Initially, the first 100 articles were selected according to the relevance in each database. The first inspection for the criteria was based on reading the titles and abstracts of the open access articles. All repeated articles were excluded as well as those not relevant to the discussion. The same procedure was taken for the restricted access articles. When there was any doubt on the exclusion criteria, a second judge analysed the article. The three authors for this study served as judges for the inclusion or exclusion of the articles. If two of the three judges agreed, the article was excluded or included. When the final database for analysis was completed, all articles were read completely in order to register all relevant details for further analysis. The studies were organized by journal, year of publication, population age, spoken and written language, main goal, experimental approach, type of study (theoretical, assessment, intervention etc.), measures used, and conclusions. In the present study, we concentrated on the discussion of the spoken language and writing system.

\section{RESULTS}

The dada was retrieved by means of a systematic review of the literature on PubMed (3.1 million articles), Science Direct (12,503,365 articles), and SciELO (478,674 articles). 
Considering the search for open access articles, we located 74 articles on PubMed, 106 on Science Direct and 12 articles on SciELO, 8 articles using the terms in English and 4 articles considering the search in Portuguese.

From the open access of PubMed database, we excluded 27 articles, 10 for not following the inclusion criteria, 9 for having different goals from the present study, 3 were repeated in other database, 2 were publish in a language other than English or Portuguese and 3 for the type of study (case study).

From the open access of Science Direct database, we excluded 92 articles, 67 for not following the inclusion criteria, 11 for having different goals from the present study, 3 were repeated in other database, 5 were publish in a language other than English or Portuguese and 6 for the type of study (case study).

From the SciELO database, when using the search of terms in English, we excluded 2 articles (one for the language of publication and one for the type of study). When using the search terms in Portuguese, we excluded 3 articles for repetition.

This way, at final analysis, we included 47 articles from PubMed, 14 articles from Science Direct and 7 articles from SciELO, in a total of 68 articles with open access.

Considering the articles found in restricted access, we selected the 100 most relevant ones, from PubMed and Science Direct. The repeated articles found in other database or at the open access were excluded. From the database PubMed, we excluded 41 articles, 7 for not following the inclusion criteria, 12 for having different goals from the present study, 21 were repeated in other database and 1 for the type of study (case study).

From de database Science Direct, we excluded 40 articles, 13 for not following the inclusion criteria, 2 for having different goals from the present study, 18 were repeated in other database and 7 for the type of study (case study). In summary, after inspection we included 59 articles from PubMed and 60 from Science Direct, a total of 119 articles from restricted access. The articles found on the SciELO database are all in open access, therefore, there were no articles found on the restricted access group.

A total of 187 articles were registered and classified according to the categories chosen for further analysis (Table 1). The complete list is in Appendix 1.

Table 1. Total number of articles found on the general search and the final number of articles after exclusions

\begin{tabular}{lcccc}
\hline & PubMed & $\begin{array}{c}\text { Science } \\
\text { Direct }\end{array}$ & SciELO & $\begin{array}{c}\text { Final } \\
\text { number }\end{array}$ \\
\hline Open access & 74 & 106 & 12 & 192 \\
$\quad$ Total found & 27 & 92 & 5 & 124 \\
$\quad$ Excluded & 47 & 14 & 7 & 68 \\
$\quad$ Included & & & & \\
Restricted access & 100 & 100 & - & 200 \\
$\quad$ Total found & 41 & 40 & - & 81 \\
Excluded & 59 & 60 & - & 119 \\
Included & 106 & 74 & 7 & 187 \\
$\quad$ Total included & & & & \\
\hline
\end{tabular}

In terms of the distribution of years of publication, there is a clear tendency of increasing the number of articles after 2009 (Figure 1). It is important to note that this review was performed on April 2014, which explains the low number of articles found in that specific year.

We found that the selected articles were published in 70 different periodicals in total, but only 14 have published five or more articles from 2004 to 2014. Figure 2 shows that Neuropsychologia is the journal with the greater number of articles $(n=22)$.

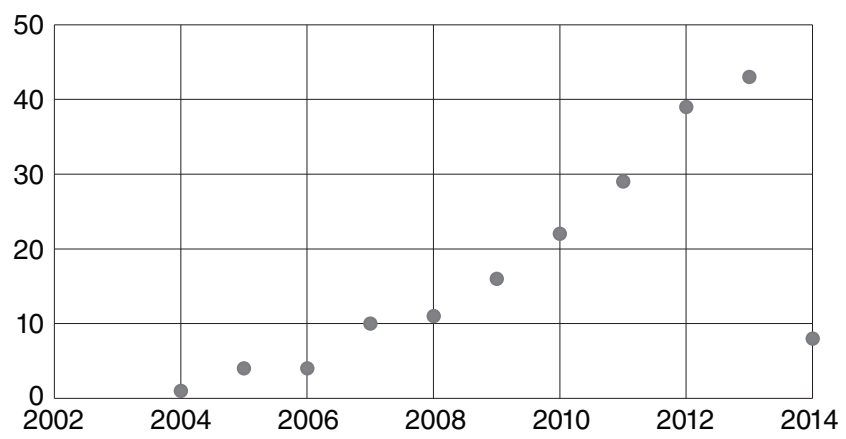

Figure 1. Distribution of publications on phonological processing and dyslexia between 2004 and 2014, by year of publication

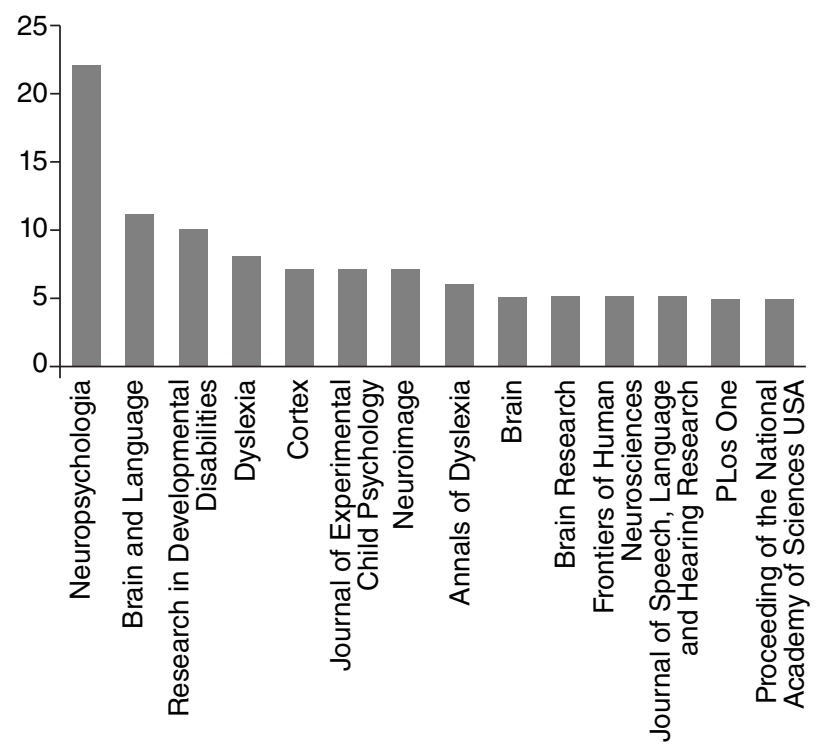

Figure 2. Distribution of journals with more than five publications on the topic "phonological processing" AND "dyslexia", between 2004 and 2014

Several countries contributed for the discussion on whether phonological processing deficit is a universal theory for explaining dyslexia. As shown in Figure 3, The United States $(n=40)$ and United Kingdom $(n=24)$ were the two more productive countries in terms of publications. Brazil was the only country in South America with scientific publications on the topic $(n=6)$. 


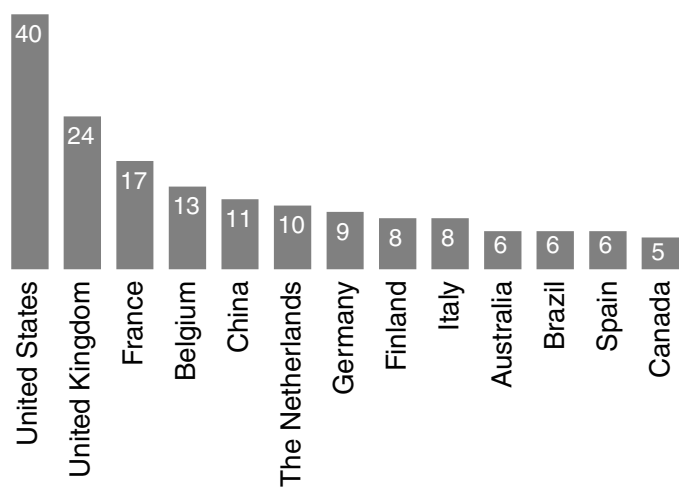

Figure 3. Countries of first authors in the publications

Regarding the spoken languages, after inspection of all articles selected in this review, we identified 18 different languages represented. Out of the 187 articles, three studies investigated phonological processing deficits in bilingual populations (Finish-Swedish; Spanish-Swedish; EnglishChinese) and one study compared phonological skills in dyslexic Spanish-, English- and Chinese-speaking children. Six articles were characterized as theoretical reviews, so there was not a specific language being investigated. Table 2 depicts the 11 most frequent languages studied. English speaking was responsible for $42 \%$ of the studies found in this review, as shown in Figure 4.

Finally, after inspection of all articles, we registered five writing system classifications: alphabetic opaque, alphabetic transparent, ideographic, logographic-syllabic, and semisyllabic (Figure 5). The most frequent writing system was alphabetic opaque (53\%) but alphabetic transparent orthographies were present in $34 \%$ of the publications. The evidence of the relation between phonological processing disorders and dyslexia comes from clinical studies, both in evaluation and intervention studies.

Table 2. Distribution of most frequent languages investigated

\begin{tabular}{lcc}
\hline Languages & Number of articles & $\%$ \\
\hline English & 71 & 38 \\
Dutch & 22 & 12 \\
French & 21 & 11 \\
German & 13 & 7 \\
Chinese & 11 & 6 \\
Finnish & 7 & 4 \\
Italian & 7 & 4 \\
Portuguese & 7 & 4 \\
Hebrew & 4 & 2 \\
Japanese & 3 & 2 \\
Spanish & 3 & 2 \\
Greek & 3 & 2 \\
Other languages & 9 & 5 \\
Does not apply & 6 & 3 \\
Total & 187 & 100 \\
\hline
\end{tabular}

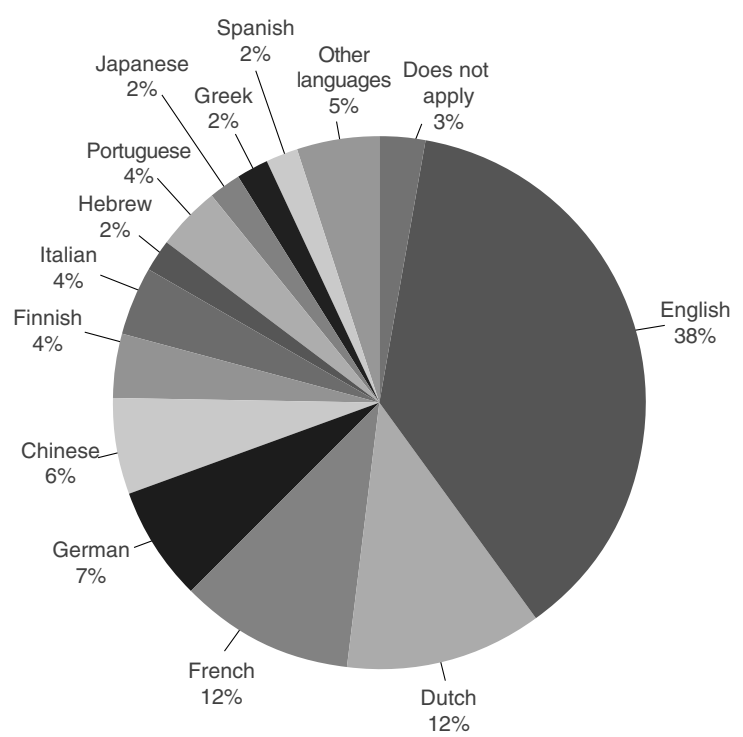

Figure 4. Distribution of articles according to the language investigated

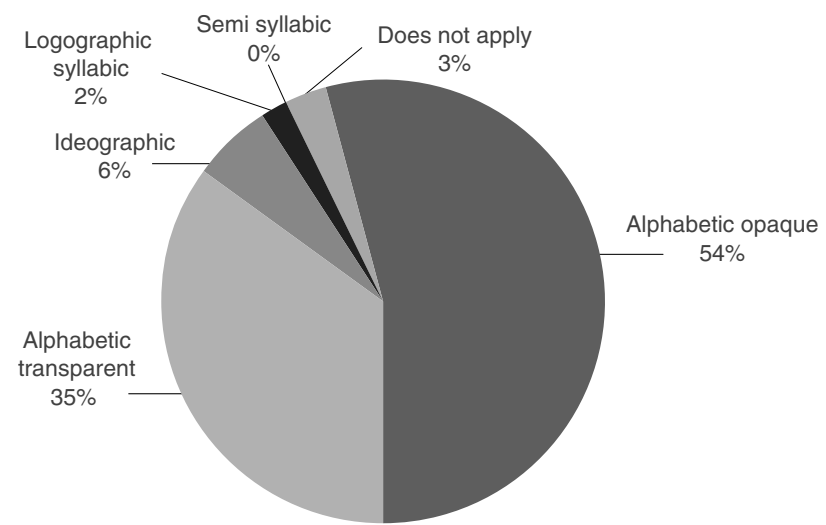

Figure 5. Distribution of writing systems and their classifications represented in the review

\section{DISCUSSION}

There is a wide spread knowledge on the phonological difficulties found in individuals with dyslexia. Some authors claim that underlying phonological processing deficits would exist for all languages, but that there would be differences in the severity of written language impairments, due to differences in orthographic consistency ${ }^{(5)}$. In other words, we investigated whether this hypothesis also holds for dyslexia in more consistent orthographies, since the phonological code is more accessible in these languages, unlike in English. The present study had the purpose to explore, with a systematic review of the literature, the relation of phonological processing deficits hypothesis with dyslexia, in terms of their universal validity.

The results show a steady increase in publications from 2004 to 2014, which indicates the relevance of the debate and the need for understanding the origin of dyslexia in recent years. From the 187 articles, some are theoretical in nature ${ }^{(6)}$, others describe intervention programs based on phonological abilities $^{(7)}$, and most of them are experimental or clinical studies ${ }^{(8,9)}$. 
In terms of the numbers of articles published, we found a wide variety of periodicals with relevant publications showing the interdisciplinary status of the discussion. The papers were found in journals representing the following areas of interest: Education, Psychology, Speech-Language Pathology, Audiology, Linguistics, and Computer Sciences.

To investigate the nature of word reading in various languages, a meta-analysis provided support for the existence of a universal reading network consisting of the left superior temporal gyrus (LSTG), the left inferior frontal gyrus (LIFG), the left occipitotemporal region, and the midfusiform Gyrus ${ }^{(10)}$. The results of this systematic review show that the universal nature of reading holds for reading disabilities, such as the ones found in dyslexia. The phonological nature of such deficits is evident for different spoken languages and different types of writing systems and orthographies ${ }^{(11)}$.

From the studies selected in the present review, it is clear that reading problems associated with dyslexia differ in regular orthographies such as Finnish ${ }^{(12)}$ as compared to less regular orthographies such as French ${ }^{(13)}$. However, the underlying cause found in phonological processing skills holds for all levels of orthographic consistencies.

The relation between phonological and orthographic processing is also explored. In recent studies, the associations between auditory temporal processing and phonological processing, and between visual processing and orthographic processing, have received some support, but a lot of criticism as well ${ }^{(14)}$. Although it is not conclusive from the analysis presented here, only a small number of children with dyslexia have reported auditory or visual processing deficits. This heterogeneity of the dyslexic population may have led to such contrasting results.

The origin of phonological processing abilities in dyslexia remains to be established. Some studies are already investigating whether the failure is found on phonological representations or in the process to access these representations during reading ${ }^{(15)}$. No matter which research approach is chosen, cross-linguistic and multidimensional aspects of dyslexia have to be considered.

\section{CONCLUSION}

The phonological processing hypothesis was a valid explanation for dyslexia symptoms in a wide variety of spoken languages and writing systems.

The findings of this review add to a growing number of studies to suggest that the relationship between phonological abilities and reading is influenced by the characteristics of the orthography. The exact nature of such phonological deficits should be subjected to cross-linguistic comparisons, taking into account systematic differences of the orthographic and phonological characteristics of the languages.

*ALGPN was the principal investigator and responsible for conception and study design, data analysis, interpretation of data, correction of written manuscript and final approval of the version to be published. ECF was responsible for data acquisition, data analysis, manuscript editing, revising the study critically, final approval of the version to be published. JPAB was responsible for data acquisition, data analysis, revising the study critically, final approval of the version to be published.

\section{REFERENCES}

1. Habib M. The neurological basis of developmental dyslexia: an overview and working hypothesis. Brain. 2000;123(12):2373-99.

2. Vellutino FR, Fletcher JM, Snowling MJ, Scanlon DM. Specific reading disability (dyslexia): what have we learned in the past four decades? J Child Psychol Psychiatry. 2004;45(1):2-40.

3. Boada R, Pennington BF. Deficient implicit phonological representations in children with dyslexia. J Exp Child Psychol. 2006;95(3):153-93.

4. Aro M, Wimmer H. Learning to read: English in comparison to six more regular orthographies. Appl Psycholinguist. 2003;24(4):621-35.

5. Landerl K, Wimmer H, Frith U. The impact of orthographic consistency on dyslexia: a German-English comparison. Cognition. 1997;63(3):315-34.

6. Ramus F. Neuroimaging sheds new light on the phonological deficit in dyslexia. Trends Cogn Sci. 2014;18(6):274-5.

7. Germano GD, Pinheiro FH, Cardoso ACV, Santos LCA, Padula NAMR, Capellini SA. Relação entre achados em neuroimagem, habilidades auditivas e metafonológicas em escolares com dislexia do desenvolvimento. Rev Soc Bras Fonoaudiol. 2009;14(3):315-22.

8. Zhou Y, McBride-Chang C, Law AB, Li T, Cheung AC, Wong AM, et al. Development of reading-related skills in Chinese and English among Hong Kong Chinese children with and without dyslexia. J Exp Child Psychol. 2014;122:75-91.

9. van Ermingen-Marbach M, Grande M, Pape-Neumann J, Sass K, Heim S. Distinct neural signatures of cognitive subtypes of dyslexia with and without phonological deficits. NeuroImage: Clinical. 2013;2:477-90.

10. Bolger DJ, Hornickel J, Cone NE, Burman DD, Booth JR. Neural correlates of orthographic and phonological consistency effects in children. Hum Brain Mapp. 2008;29(12):1416-29.

11. Goulandris N. Dyslexia in different languages: cross-linguistic comparisons. London: Whurr Publishers; 2003.

12. Laasonen M, Salomaa J, Cousineau D, Leppämäki S, Tani P, Hokkanen L, et al. Project DyAdd: visual attention in adult dyslexia and ADHD. Brain Cog. 2012;80(3):311-27.

13. Lallier M, Donnadieu S, Valdois S. Investigating the role of visual and auditory search in reading and developmental dyslexia. Front Hum Neurosci. 2013;7:597.

14. Georgiou GK, Papadopoulos TC, Zarouna E, Parrila R. Are auditory and visual processing deficits related to developmental dyslexia? Dyslexia. 2012;18(2):110-29.

15. Navas ALGP. What phonological deficit? Rev Soc Bras Fonoaudiol. 2007;12(4):341-2. 
Appendix 1. List of the 187 articles included for the analysis

\begin{tabular}{|c|c|c|c|c|}
\hline $\mathrm{N}$ & Authors & Year & Title & Journal \\
\hline 1. & Bonte and Blomert & 2004 & $\begin{array}{l}\text { Developmental dyslexia: ERP correlates of anomalous phonological processing during } \\
\text { spoken word recognition }\end{array}$ & Cogn Brain Res \\
\hline 2. & Catts et al. & 2005 & Are specific language impairment and dyslexia distinct disorders? & $\begin{array}{l}\text { J Speech Lang } \\
\text { Hear Res }\end{array}$ \\
\hline 3. & Giraud et al. & 2005 & $\begin{array}{l}\text { Auditory evoked potential patterns to voiced and voiceless speech sounds in adult } \\
\text { developmental dyslexics with persistent deficits }\end{array}$ & Cereb Cortex \\
\hline 6. & Hoeft et al. & 2006 & $\begin{array}{l}\text { Neural basis of dyslexia: a comparison between dyslexic and nondyslexic children } \\
\text { equated for reading ability }\end{array}$ & J Neurosci \\
\hline 7. & Boets et al. & 2006 & $\begin{array}{l}\text { Auditory temporal information processing in preschool children at family risk for dyslexia: } \\
\text { relations with phonological abilities and developing literacy skills }\end{array}$ & Brain Lang \\
\hline 11. & Rüsseler et al. & 2007 & $\begin{array}{l}\text { Semantic, syntactic, and phonological processing of written words in adult developmental } \\
\text { dyslexic readers: an event-related brain potential study }\end{array}$ & BMC Neurosci \\
\hline 12. & $\begin{array}{l}\text { Shankarnarayan } \\
\text { and Maruthy }\end{array}$ & 2007 & Mismatch negativity in children with dyslexia speaking Indian languages & Behav Brain Funct \\
\hline 13. & Veuillet et al. & 2007 & $\begin{array}{l}\text { Auditory processing disorder in children with reading disabilities: effect of } \\
\text { audiovisual training }\end{array}$ & Brain \\
\hline 14. & Roach and Hogben & 2007 & Impaired filtering of behaviourally irrelevant visual information in dyslexia & Brain \\
\hline 15. & Bruno et al. & 2007 & Auditory word identification in dyslexic and normally achieving readers & J Exp Child Psychol \\
\hline 16. & Boets et al. & 2007 & $\begin{array}{l}\text { Speech perception in preschoolers at family risk for dyslexia: Relations with low-level } \\
\text { auditory processing and phonological ability }\end{array}$ & Brain Lang \\
\hline 22. & Kibby et al. & 2008 & $\begin{array}{l}\text { A quantitative magnetic resonance imaging analysis of the cerebellar deficit } \\
\text { hypothesis of dyslexia }\end{array}$ & J Child Neurol \\
\hline 23. & Frye et al. & 2008 & Splenium microstructure is related to two dimensions of reading skill & Neuroreport \\
\hline 24. & $\begin{array}{l}\text { Germano and } \\
\text { Capellini }\end{array}$ & 2008 & $\begin{array}{l}\text { Eficácia do programa de remediação auditivo-visual computadorizado em escolares } \\
\text { com dislexia }\end{array}$ & Pró-Fono \\
\hline 25. & Capellini et al. & 2008 & $\begin{array}{l}\text { Relação entre habilidades auditivas e fonológicas em crianças com dislexia do } \\
\text { desenvolvimento }\end{array}$ & Psicol Esc Educ \\
\hline 26. & Seki et al. & 2008 & Reading ability and phonological awareness in Japanese children with dyslexia & Brain Dev \\
\hline 27. & Ziegler et al. & 2008 & $\begin{array}{l}\text { Developmental dyslexia and the dual route model of reading: simulating individual } \\
\text { differences and subtypes }\end{array}$ & Cognition \\
\hline 28. & $\begin{array}{l}\text { Lassus-Sangosse } \\
\text { et al. }\end{array}$ & 2008 & Sequential or simultaneous visual processing deficit in developmental dyslexia? & Vision Res \\
\hline 29. & Thomson et al. & 2008 & $\begin{array}{l}\text { Rhythmic processing in children with developmental dyslexia: auditory and motor rhythms } \\
\text { link to reading and spelling }\end{array}$ & J Physiol Paris \\
\hline 30. & Spironelli et al. & 2008 & $\begin{array}{l}\text { Dysfunctional hemispheric asymmetry of theta and beta EEG activity during linguistic } \\
\text { tasks in developmental dyslexia }\end{array}$ & Biol Psychol \\
\hline 31. & $\begin{array}{l}\text { Miller and } \\
\text { Kupfermann }\end{array}$ & 2009 & $\begin{array}{l}\text { The role of visual and phonological representations in the processing of written words by } \\
\text { readers with diagnosed dyslexia: evidence from a working memory task }\end{array}$ & Ann Dyslexia \\
\hline 32. & Liu et al. & 2009 & Speech perception deficits by Chinese children with phonological dyslexia & J Exp Child Psychol \\
\hline 33. & Abrams et al. & 2009 & Abnormal cortical processing of the syllable rate of speech in poor readers & J Neurosci \\
\hline
\end{tabular}


Appendix 1. Continuation

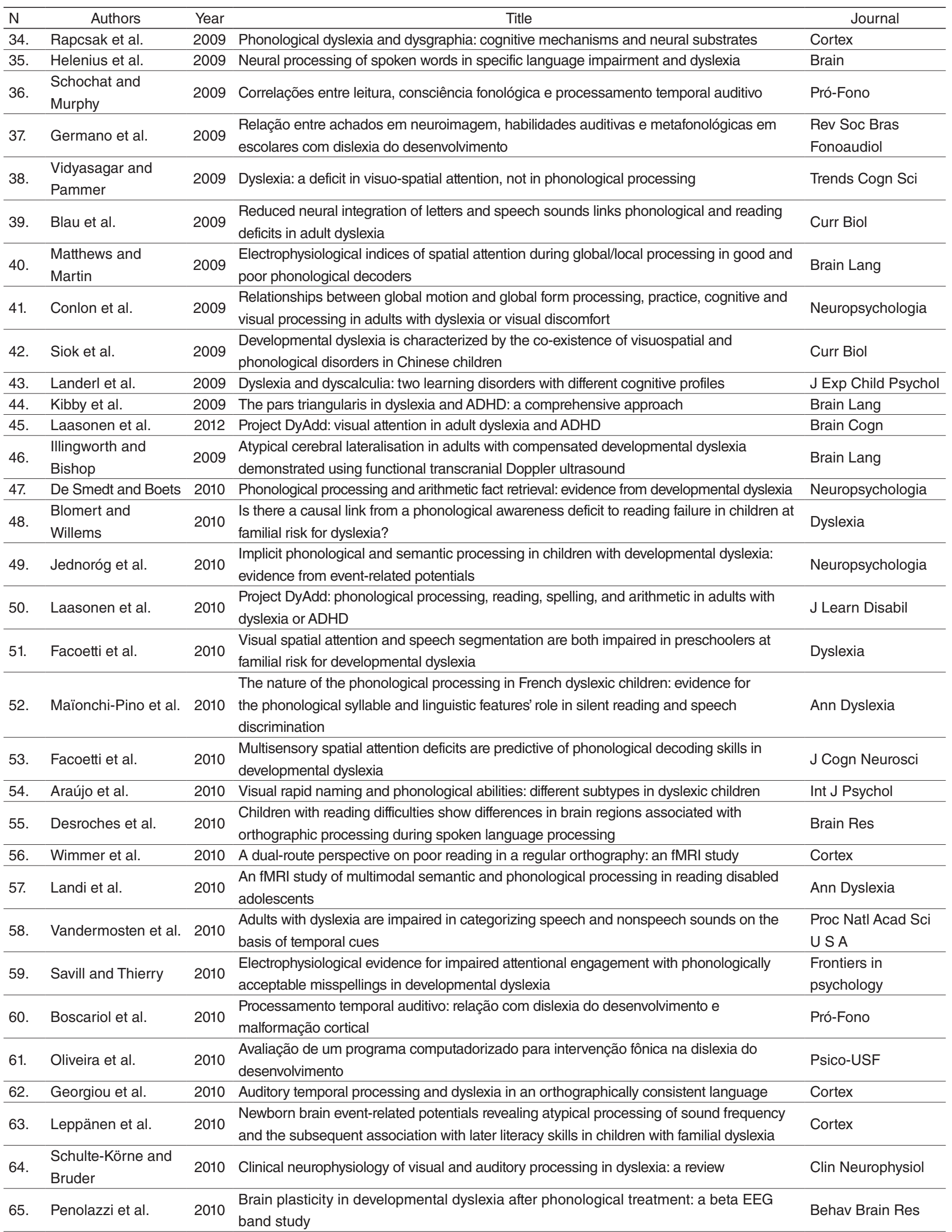


Appendix 1. Continuation

\begin{tabular}{|c|c|c|c|c|}
\hline $\mathrm{N}$ & Authors & Year & Title & Journal \\
\hline 66. & Wang et al. & 2010 & $\begin{array}{l}\text { The visual magnocellular pathway in Chinese-speaking children with developmental } \\
\text { dyslexia }\end{array}$ & Neuropsychologia \\
\hline 67. & Lallier et al. & 2010 & $\begin{array}{l}\text { Behavioral and ERP evidence for amodal sluggish attentional shifting in } \\
\text { developmental dyslexia }\end{array}$ & Neuropsychologia \\
\hline 68. & Menghini et al. & 2010 & $\begin{array}{l}\text { Different underlying neurocognitive deficits in developmental dyslexia: a } \\
\text { comparative study }\end{array}$ & Neuropsychologia \\
\hline 70. & Savill and Thierry & 2011 & $\begin{array}{l}\text { Reading for sound with dyslexia: evidence for early orthographic and late phonological } \\
\text { integration deficits }\end{array}$ & Brain Res \\
\hline 71. & Tanaka et al. & 2011 & The brain basis of the phonological deficit in dyslexia is independent of IQ & Psychol Sci \\
\hline 72. & Brooks et al. & 2011 & $\begin{array}{l}\text { Letter naming and letter writing reversals in children with dyslexia: momentary } \\
\text { inefficiency in the phonological and orthographic loops of working memory }\end{array}$ & Dev Neuropsychol \\
\hline 76. & Goswami et al. & 2011 & $\begin{array}{l}\text { Language-universal sensory deficits in developmental dyslexia: English, Spanish, } \\
\text { and Chinese }\end{array}$ & J Cogn Neurosci \\
\hline 77. & Froyen et al. & 2011 & $\begin{array}{l}\text { Evidence for a specific cross-modal association deficit in dyslexia: an electrophysiological } \\
\text { study of letter-speech sound processing }\end{array}$ & Dev Sci \\
\hline 78. & van der Mark et al. & 2011 & $\begin{array}{l}\text { The left occipitotemporal system in reading: disruption of focal fMRI connectivity to left } \\
\text { inferior frontal and inferior parietal language areas in children with dyslexia }\end{array}$ & Neuroimage \\
\hline 79. & Lehongre et al. & 2011 & Altered low- $\gamma$ sampling in auditory cortex accounts for the three main facets of dyslexia & Neuron \\
\hline 80. & Hämäläinen et al. & 2011 & $\begin{array}{l}\mathrm{N} 1, \mathrm{P} 2 \text { and T-complex of the auditory brain event-related potentials to tones with varying } \\
\text { rise times in adults with and without dyslexia }\end{array}$ & Int J Psychophysiol \\
\hline 81. & You et al. & 2011 & $\begin{array}{l}\text { Neural deficits in second language reading: fMRI evidence from Chinese children with } \\
\text { English reading impairment }\end{array}$ & Neuroimage \\
\hline 86. & $\begin{array}{l}\text { Messaoud-Galusi } \\
\text { et al. }\end{array}$ & 2011 & $\begin{array}{l}\text { Investigating speech perception in children with dyslexia: is there evidence of a consistent } \\
\text { deficit in individuals? }\end{array}$ & $\begin{array}{l}\text { J Speech Lang } \\
\text { Hear Res }\end{array}$ \\
\hline 87. & Hoeft et al. & 2011 & Neural systems predicting long-term outcome in dyslexia & $\begin{array}{l}\text { Proc Natl Acad Sci } \\
\text { U S A }\end{array}$ \\
\hline 88. & Araújo et al. & 2011 & What does rapid naming tell us about dyslexia? & $\begin{array}{l}\text { Avances en } \\
\text { Psicología } \\
\text { Latinoamericana }\end{array}$ \\
\hline 89. & Dujardin et al. & 2011 & $\begin{array}{l}\text { Behavioral performances in participants with phonological dyslexia and different patterns } \\
\text { on the N170 component }\end{array}$ & Brain Cogn \\
\hline 90. & Raschle et al. & 2011 & Structural brain alterations associated with dyslexia predate reading onset & Neuroimage \\
\hline 91. & Vandermosten et al. & 2011 & $\begin{array}{l}\text { Impairments in speech and nonspeech sound categorization in children with dyslexia are } \\
\text { driven by temporal processing difficulties }\end{array}$ & Res Dev Disabil \\
\hline 92. & Huss et al. & 2011 & $\begin{array}{l}\text { Music, rhythm, rise time perception and developmental dyslexia: perception of musical } \\
\text { meter predicts reading and phonology }\end{array}$ & Cortex \\
\hline 93. & Nittrouer et al. & 2011 & $\begin{array}{l}\text { What is the deficit in phonological processing deficits: auditory sensitivity, masking, or } \\
\text { category formation? }\end{array}$ & J Exp Child Psychol \\
\hline 94. & Koeda et al. & 2011 & Dyslexia: advances in clinical and imaging studies & Brain Dev \\
\hline 95. & Stefanics et al. & 2011 & Auditory sensory deficits in developmental dyslexia: a longitudinal ERP study & Neuroimage \\
\hline 96. & Khana et al. & 2011 & Auditory event-related potentials show altered hemispheric responses in dyslexia & Neurosci Lett \\
\hline 97. & Moores et al. & 2011 & $\begin{array}{l}\text { Adults with dyslexia exhibit large effects of crowding, increased dependence on cues, and } \\
\text { detrimental effects of distractors in visual search tasks }\end{array}$ & Neuropsychologia \\
\hline
\end{tabular}


Appendix 1. Continuation

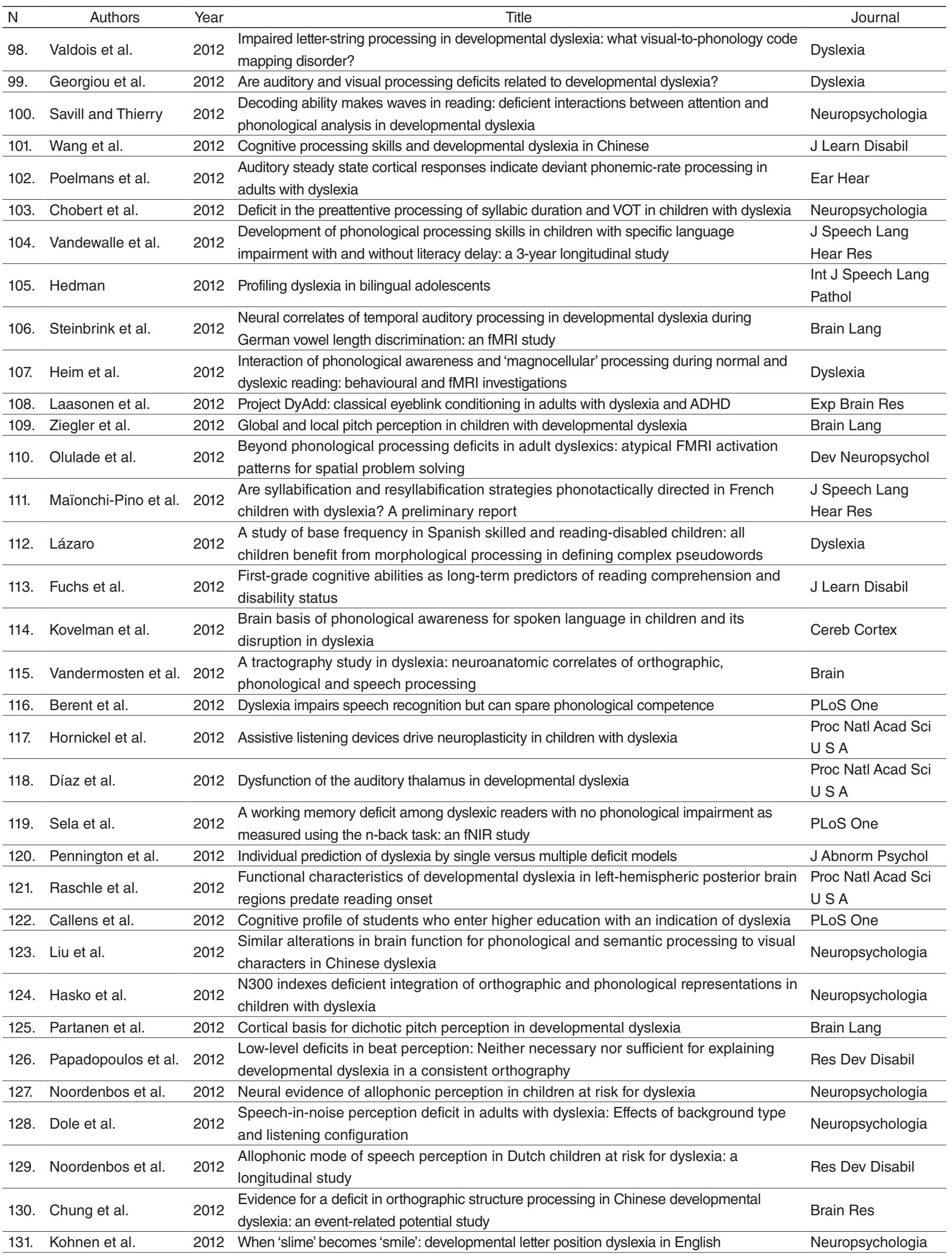


Appendix 1. Continuation

\begin{tabular}{llllll}
\hline $\mathrm{N}$ & Authors & Year & Title Journal
\end{tabular}

A comparative study of rapid naming and working memory as predictors of word

132. Aguilar-Vafaie et al. 2012 recognition and reading comprehension in relation to phonological awareness in Iranian dyslexic and normal children

133. Mejía et al.

2012 BEDA: a computerized assessment battery for dyslexia in adults

134. Olofsson et al.

2012 Learning and study strategies in university students with dyslexia: implications for teaching

135. Aboras et al.

2012 Development of a remediation program for Egyptian dyslexic children

136. Rello et al.

2012 A mobile application for displaying more accessible eBooks for people with dyslexia

137. Lallier et al.

2013

Developmental dyslexia: exploring how much phonological and visual attention span

disorders are linked to simultaneous auditory processing deficits

138. Robertson et al.

2013

139. Cantiani et al. Past-tense morphology and phonological deficits in children with dyslexia and children with language impairment

2013

140. Park and

140. Lombardino

141. Kita et al. Characterizing the morphosyntactic processing deficit and its relationship to phonology in developmental dyslexia

2013

Relationships among cognitive deficits and component skills of reading in younger and older students with developmental dyslexia

2013 Altered brain activity for phonological manipulation in dyslexic Japanese children

142. Desroches et al.

2013

143. Goswami et al.

2013

144. Noordenbos et al.

145. Berent et al.

146. Zaidan and Baran

147. Olulade et al.

148. Bloom et al.

149. Bruno et al.

150. Trecy et al. Doignon-Camus

151. et al.

2013 Deviant neural processing of phonotactic probabilities in adults with dyslexia

2013 Phonological generalizations in dyslexia: the phonological grammar may not be impaired

2013

Gaps-in-noise (GINO) test results in children with and without reading disabilities and phonological processing deficit

2013 Abnormal visual motion processing is not a cause of dyslexia

2013 Planum temporale morphology in children with developmental dyslexia

2013 Phonological processing is uniquely associated with neuro-metabolic concentration

2013 Impaired short-term memory for order in adults with dyslexia

2013

Evidence for a preserved sensitivity to orthographic redundancy and an impaired access

to phonological syllables in French developmental dyslexics

152. Kronschnabel et al.

153. Giraud and Ramus

2013

2013

154. Lallier et al.

2013

155. van Zuijen et al. 2013 In

2013 Dyslexia and fluency: parafoveal and foveal influences on rapid automatized naming

156. Jones et al.

2013 Teaching children with dyslexia to spell in a reading-writers' workshop

157. Berninger et al.

158. Mundy and Carroll

2013

159. Yang et al.

2013

160. Dole et al.

161. Boets et al.

162. Lallier et al.

163. Hasko et al. Spelling-stress regularity effects are intact in developmental dyslexia

164. White-Schwoch and Kraus

165. Power et al.

166. Soltész et al.

2013

Orthographic influences on division of labor in learning to read Chinese and English: insights from computational modeling

Gray and white matter distribution in dyslexia: a VBM study of superior temporal gyrus asymmetry

2013 Intact but less accessible phonetic representations in adults with dyslexia

2013 Investigating the role of visual and auditory search in reading and developmental dyslexia

2013 The time course of reading processes in children with and without dyslexia: an ERP study

2013

Physiologic discrimination of stop consonants relates to phonological skills in pre-readers:

a biomarker for subsequent reading ability?

2013 Neural entrainment to rhythmic speech in children with developmental dyslexia

2013 Differential entrainment of neuroelectric delta oscillations in developmental dyslexia

Is the phonological deficit in developmental dyslexia related to impaired phonological representations and to universal phonological grammar?
Procedia Soc

Behav Sci

Procedia Soc

Behav Sci

Procedia Soc

Behav Sci

AJM

Procedia Comput

Sci

Ann Dyslexia

J Learn Disabil

Neuropsychologia

Res Dev Disabil

Brain

J Speech Lang

Hear Res

Cortex

Neuroreport

Cogn Neuropsychol

Int J Audiol

Neuron

Neuropsychologia

Neuroimage

Res Dev Disabil

Ann Dyslexia

Neuroimage

Curr Opin Neurobiol

Cognition

Dev Sci

J Exp Psychol Hum

Percept Perform

Ann Dyslexia

Q J Exp Psychol

(Hove)

Biling (Camb Engl)

PLoS One

Science

Front Hum Neurosci

Front Hum Neurosci

Front Hum Neurosci

Front Hum Neurosci

PLoS One

J Exp Child Psychol 
Appendix 1. Continuation

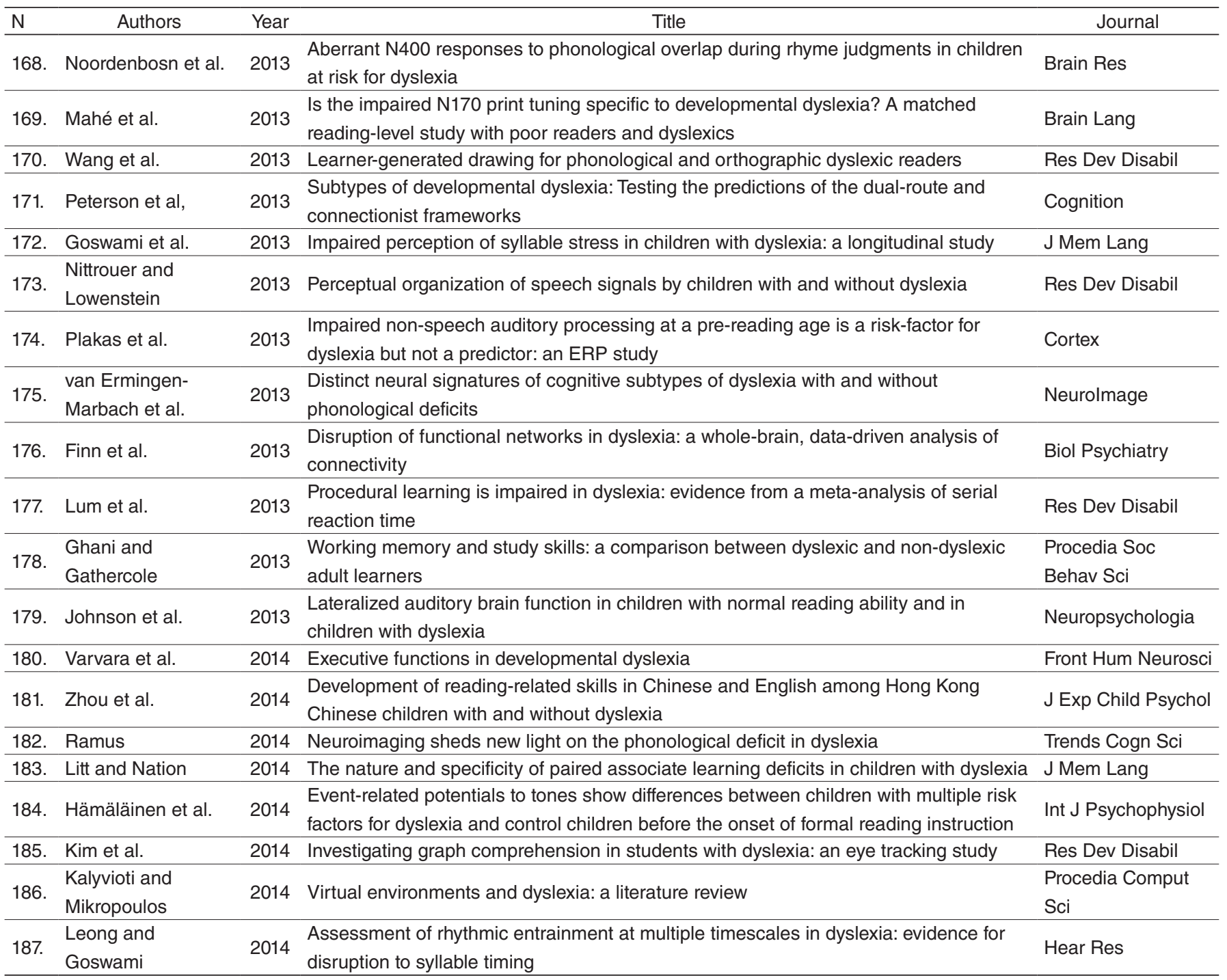

